\title{
Análise e representação de filmes em unidades de informação
}

\author{
Rosa Inês de Novais Cordeiro \\ Pós-doutora no Instituto de Psicologia (UFRJ), doutora em \\ comunicação e cultura (ECO/UFRJ). Professora da Universidade \\ Federal Fluminense (Departamento de Ciência da Informação) \\ e integrante do Programa de Pós-graduação em Ciência da \\ Informação (Ibict/UFF). E-mail: igneznovais@uol.com.br \\ Tunico Amâncio \\ Pós-doutor pela Sorbonne Nouvelle-Université Paris III, \\ doutor em cinema (USP), professor da Universidade Federal \\ Fluminense (Departamento de Cinema e Vídeo), integrante \\ do Programa de Pós-graduação em Comunicação (UFF) \\ e curtametragista. E-mail: tunico@cruiser.com.br
}

\section{INTRODUÇÃO}

Este artigo é resultado de uma pesquisa sobre a possibilidade de análise de filmes no âmbito descritivo, mas centrada principalmente na análise de conteúdo dos filmes de ficção, para aplicação em unidades de informação como cinematecas, videotecas, bibliotecas e arquivos. Tais unidades possuem grandes "estoques de informação"* (acervos) e necessitam de princípios aplicáveis na indexação e na organização das coleções para disponibilizar o seu uso. $\mathrm{O}$ estudo tem como base critérios que emergiram das áreas da ciência da informação e documentação, bem como do cinema, além das interfaces com outras especialidades do conhecimento.

A pesquisa constitui-se de duas etapas investigativas, com características singulares, mas, ao mesmo tempo, integradas, progressivas e coesas. Atualmente está sendo iniciada a terceira etapa, que se refere à informatização dos procedimentos metodológicos. Posteriormente, em 2006, pretende-se disponibilizar a terceira etapa para a comunidade acadêmica e demais interessados no assunto, tendo em vista a incorporação de sugestões e avaliações.

Neste artigo, a intenção é comunicar os resultados da pesquisa referentes à primeira e a segunda etapa, pois eles são substanciais quanto aos princípios norteadores para a indexação de filmes de ficção**.

A primeira etapa foi desenvolvida por grupo interdisciplinar de estudiosos que inicialmente discutiram a questão da análise de filmes, para sua representação (indexação) em unidades de informação. $\mathrm{O}$ grupo era coordenado pelos autores deste artigo e foi formado por integrantes ${ }^{* * *}$, à época, do Laboratório de Investigação Audiovisual (LIA),

\footnotetext{
* Expressão usada por Aldo Albuquerque Barreto.

${ }^{* *}$ Para fins de esclarecimento, embora não seja o objetivo deste trabalho tal discussão, pode-se pensar no sentido lato da diferença entre representação fílmica e análise fílmica, considerando que uma é o ato, o evento, a outra é este evento submetido a uma leitura de natureza avaliativa e/ou crítica. Entretanto, no sentido stricto da representação documentária, a indexação possui duas grandes etapas, a análise do conteúdo do documento e a sua tradução (síntese) para a linguagem do sistema de recuperação da informação. Há também a possibilidade do uso das palavras análise para a interpretação do conteúdo do documento pelo indexador e a palavra representação para a conversão do conteúdo interpretado e selecionado pelo indexador para categorias do SRI que serão usadas como pontos de acesso aos documentos.

*** Rosa Inês Novais Cordeiro, Tunico Amâncio, Heloísa Rios Gusmão, Cristina Emmerick, Lena Mendes, Leandro Mendonça.
} 
do Instituto de Arte e Comunicação Social (IACS) e da Universidade Federal Fluminense (UFF).

A segunda etapa da pesquisa teve o incentivo do Conselho Nacional de Desenvolvimento Científico e Tecnológico (CNPq) por meio do Programa Institucional de Bolsas de Iniciação Científica (Pibic) e com a parceira da UFF, no período de 1999-2000. Nesta fase, as discussões resultantes da primeira etapa foram consolidadas, mas foram ampliadas e desenvolvidas a metodologia, a testagem sistemática dos princípios propostos na indexação dos filmes, as avaliações e os ajustes. Em conseqüência, chegou-se à proposição de um possível modelo de indexação*; porém deve ser enfatizado que este modelo de indexação é uma opção entre outros existentes.

A partir de então, os resultados alcançados são cotejados com a literatura produzida sobre o tema e, portanto, tem sido realizado o acompanhamento das discussões sobre o assunto, além da apresentação e discussão dessa proposta em sala de aula. Do mesmo modo, estão sendo realizadas testagens assistemáticas, para reavaliação dos princípios e, como foi dito, está havendo a tentativa de viabilizar a informatização da proposta e dos procedimentos de recuperação das informações dos filmes. Diante disso, nossa proposição, nesta terceira etapa (2004/2006), é usar o modelo proposto na indexação e recuperação dos filmes produzidos pelos alunos do Curso de Graduação em Cinema e Vídeo da UFF, disponibilizar as informações fílmicas e metodológicas para a comunidade e também avaliar e agregar sugestões que resultem desse intercâmbio e transferência de conhecimentos investigativos, empíricos e tácitos.

\section{SOBRE O OBJETO DE ESTUDO: OS FILMES}

A amostra foi composta por 100 filmes de ficção. Na primeira etapa, foram analisados e indexados filmes brasileiros e também os produzidos pela indústria americana que estavam na mídia. Os filmes foram vistos em fitas em VHS. Deste universo, destaca-se, em particular na segunda etapa, a intenção de testar o modelo de indexação em uma obra completa e expressiva do cinema brasileiro. Diante disso, realizaram-se a análise e a indexação de todos os filmes disponíveis para o acesso da obra do cineasta Nelson Pereira dos Santos. Utilizou-se a obra cinematográfica dos longas-metragens roteirizados e/ ou dirigidos pelo cineasta. Ainda, foram os seguintes fatores que influenciaram a escolha da amostra dos filmes brasileiros: o fato de a produção do cineasta ser vasta e heterogênea quanto ao gênero, dramaturgia e temáticas

" Estes resultados foram apresentados no Seminário de Iniciação Científica e Prêmio UFF Vasconcellos Torres de Pesquisa, Niterói, 2000. e de retratar a produção do cinema brasileiro em épocas diferentes. Por exemplo, quanto aos aspectos propriamente cinematográficos da extensa obra do cineasta: sua relação com a literatura/adaptações (Vidas Secas, Memórias do Cárcere); com a etnografia e a história (Como era Gostoso Meu Francês), com questões étnicas (Tenda dos Milagres), com a tradição melodramática latino-americana (Cinema de Lágrimas).

Os filmes analisados e indexados: Rio 40 Graus (1956); Rio, Zona Norte (1957); Mandacaru Vermelho (1961); Boca de Ouro (1963); Vidas Secas (1963); El Justiceiro (1967); Fome de Amor (1968); Azyllo Muito Louco (1971); Como era Gostoso o Meu Francês (1972); O Amuleto de Ogum (1975); Tenda dos Milagres (1977); Estrada da Vida - Milionário e José Rico (1981); Memórias do Cárcere (1984); Jubiabá (1987); A Terceira Margem do Rio (1994) e Cinema de Lágrimas (1995).

\section{EMBASAMENTO TEÓRICO E PROCEDIMENTOS METODOLÓGICOS}

Na literatura, foram levantados documentação, normas, códigos e manuais referentes à descrição de filmes, entre os quais podem ser destacados o Código de Catalogação Anglo-Americano (AACR), as recomendações da Federação Internacional de Arquivos de Filmes (Fiaf), a Norma Geral Internacional de Descrição Arquivística (Isad [G]) e a Norma Internacional de Registro de Autoridade Arquivística para Entidades Coletivas, Pessoas e Famílias (Issar [CPF]), além de visitas técnicas a instituições voltadas para acervos de cinema.

O objeto principal de estudo era a análise do conteúdo dos filmes. Para tal, realizaram-se pesquisas na literatura referentes aos procedimentos usados em unidades de informação, para ampliar a indexação e a recuperação da tematicidade (aboutness) dos filmes. Também tornouse fundamental para as discussões a literatura de cinema referente à análise fílmica*. O objetivo, entretanto, era indagar sobre procedimentos de análise que pudessem ser viabilizados nos domínios da práxis, ou seja, operacionalizados para um sistema de recuperação da informação.

É importante acentuar que a operacionalização implicava a articulação entre os conjuntos unívocos tanto de

\footnotetext{
"A palavra "fílmico" pertence à cultura de domínio da área de cinema sendo assim usada de forma habitual na literatura de cinema, além de constar de dicionário da língua portuguesa. Cf. AUMONT, Jacques; MARIE, Michel. Dicionário teórico e crítico de cinema. Campinas, SP: Papirus, 2003; VANOYE, Francis; GOLIOT-LÉTÉ, Anne. Ensaio sobre a análise fílmica. Campinas: Papirus, 1994; HOUAISS, Antonio. Dicionário Houaiss da língua portuguesa. Rio de Janeiro: Objetiva, 2004.
} 
documentos como de usuários, e o conjunto organizacional, mesmo que essa interlocução entre conjuntos fosse, em alguns momentos, de natureza simulada.

Portanto, [...] o conjunto de documentos de um SRI* [...] deverá ser trabalhado de forma articulada com o conjunto de usuários e o conjunto-unidade organizacional, além de considerar a condição 'volume` documentário. O potencial informativo de um documento [...] não implica somente conhecer a tematicidade de tal documento, mas proceder à sua análise, sob diferentes pontos de acesso candidatos à indexação, seja quanto à forma e/ou conteúdo. Este processo de múltipla indexação permite que se faça a sua polirrepresentação tentando-se atingir os usuários em potencial, ou seja, o uso da informação a posteriori. Entretanto, deverá ser estabelecido um mínimo-máximo relevante, de modo a se tornar indexável (CORDEIRO, 2000, p. 87-88).

Nesse caso, algumas condições deveriam ser atendidas na proposta para a análise e a representação (indexação) dos filmes, pois a produção de sentido compreende a leitura do filme decorrente de um "processo de constituição da subjetividade", isto é, a "interlocução entre sujeitos e, como tal, o espaço de construção e circulação de

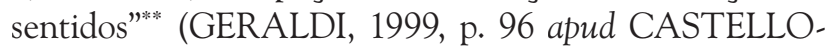
BRANCO, 2003, p. 47). Em conseqüência, as condições referidas eram almejar o critério de análise compartilhada (a análise de um filme não é um critério individual, mas deverá ser realizada para responder a perguntas coincidentes de um grupo de usuários), estabelecer um mínimo-máximo relevante de pontos de acesso para a indexação em três níveis e possibilitar o acesso coletivo a informações, nos diferentes níveis de usuários.

Dessas condições, emergem algumas considerações que devem ser ponderadas. $\mathrm{O}$ artefato informacional - o filme - é o resultado de atividade proveniente de uma expressão artística produzida comumente de forma coletiva, mas é também uma atividade que está no domínio do científico e do tecnológico. Desta maneira, os sujeitos envolvidos na produção e recepção do artefato são de naturezas marcadamente diversa e ímpar, cujos pontos de vista sobre a obra cinematográfica navegam no domínio do subjetivo. Portanto, a possibilidade de viabilizar o acesso coletivo dos usuários às informações dos filmes conduz a uma argumentação no viés do pensamento de Tarde sobre o "contágio imitativo".

\footnotetext{
* Sistema de Recuperação de Informação.

** A idéia dos autores citados foi expandida para o universo da leitura fílmica.
}

Para esse autor, e com a precisão cirúrgica da explicação de Themudo (2002, p. 63), lembra-se que na visão de Durkheim, o social

[...] é explicado somente a partir das intervenções multiplicadas de um significante social, através dos grandes territórios institucionais (família, escola, trabalho). Sendo assim, as cartografias individuais deverão ser sempre um decalque das representações coletivas. Toda ação se caracteriza pela intervenção entre um significante geral e uma ação específica [grifo nosso]. Há como que uma razão de série dos fenômenos sociais expressa por Durkheim através da noção de consciência coletiva A subjetividade se explicaria sempre pela intervenção de uma representação geral. O conceito de hábito, ou costume, remete sempre, em Durkheim, aos imperativos da lei existente na noção de consciência coletiva. A semelhança social se instaura sempre ou pela identidade do meio que comporta a representação ou pela filiação de uma consangüinidade (TARDE apud THEMUDO, 2002, p. 63).

Em contrapartida, para Tarde, citado por Themudo, 2002, p.6364), "[...] tal semelhança irá se referir sempre a um contágio imitativo. 'Assim, a semelhança dos produtos artísticos, por exemplo, não prova nada em favor da consangüinidade e revela somente um contágio imitativo"”.

Diante disso, talvez se justifiquem as semelhanças existentes em determinadas obras resultantes de manifestações artísticas e, quem sabe, apresentadas em muitos dos filmes já produzidos.

Porventura, pode-se especular que a constância das indagações dos indivíduos (usuários), ou seja, dos interesses informacionais em uma unidade de informação, possa ser justificada pelo efeito do "contágio imitativo"?

Essas indagações poderão ser matriciadas e potencializadas pela proposta de ampliar este "contágio imitativo" usandose o potencial informativo do documento fílmico que normalmente não se indaga na práxis.

Daí a enunciação da importância e da necessidade de estudos de análises de filmes realizadas na área de cinema e campos adjacentes, para que elas possam ser matriciadas e analisadas na área da representação documentária e, uma vez viáveis de forma teórica e técnica, possam traduzirse em atividades operacionais e, em conseqüência, ser divulgadas e implantadas na prática dessas unidades. Potencializar-se-ia ainda a função dessas unidades de informação para a disseminação e ampliação de conhecimentos da sociedade. 
O pressuposto do "contágio imitativo" pode ser ponderado, no percentual referente às perguntas coincidentes que freqüentemente ocorrem em uma unidade de informação. A partir daí, é feita relação dos conjuntos de usuários com conjuntos de documentos e níveis de usuários com níveis de indexação.

Os níveis referem-se ao grau de exaustividade dos pontos de acesso às informações que foram indexadas no filme. O primeiro nível, apresentado neste artigo, refere-se à indexação da informação dos filmes para o grande público ou para o público leigo. O segundo nível destina-se ao público iniciado em assuntos filmográficos, e o terceiro nível é para o especialista em cinema.

\section{RESULTADOS ALCANÇADOS: A ANÁLISE DOS FILMES PARA SUA REPRESENTAÇÃO EM UNIDADES DE INFORMAÇÃO}

Foram feitas sete versões de matrizes dos filmes com campos e critérios de indexação (metadados). Esta matriz é composta de duas grandes partes, que foram denominadas descrição fílmica (descrição de filmes) e análise da representação fílmica (análise e representação do conteúdo de filmes).

Entretanto, carece explicar que a parte descritiva da matriz desenvolvida teve como processo de divisão seis categorias que emergiram e se adaptaram ao objeto de estudo, o filme, a partir da essência dos fundamentos das categorias do Classification Research Group (CRG), e foram nomeadas como identificação (produto final/ personalidade), acervo (entidade) ${ }^{*}$, caracterização (propriedades), apresentação (forma de apresentação/ expressão-som/diálogo), comercialização (operações) e ficha técnica resumida (agentes).

No que se refere às informações descritivas, só serão citados alguns campos que possuam particularidades que mereçam alusão, tais como:

- Título do filme - foram incluídos o título no Brasil e o título original, quando foi o caso, do mesmo filme.

- Diálogos/dublagem/degendas/intertítulos - foram nomeados de forma específica. Por exemplo: em um mesmo filme, pode-se ter diálogos em português/espanhol e legendas em português.

\footnotetext{
" No caso específico deste estudo, houve a necessidade de separação das categorias personalidade (que na concepção do CRG deve ser entendida como produto final) e entidade.
}

- Ficha técnica resumida - produtor (pessoa física e/ou produtor executivo); diretor (indicar também outros cargos próprios da assistência de direção, como co-diretor, diretor adjunto, assistente(s) de direção); fotógrafo (diretor de fotografia); montador; compositor (autor da trilha sonora); roteiro original (criador ou adaptador da obra cinematográfica); direção de arte; efeitos especiais; elenco principal (sempre que possível nomeou-se de acordo com a ficha técnica apresentada no filme, e ainda incluiuse o nome do artista e, entre parênteses, o nome de seu personagem na trama). Poderão ser incluídos outros créditos considerados fundamentais.

Na segunda parte da matriz fílmica, ou seja, na análise da representação do conteúdo dos filmes, foi desenvolvida a análise da narrativa fílmica. Os agrupamentos aos quais se chegou quando articulados com a categorização do $\mathrm{CRG}$ referem-se fundamentalmente ao produto final, por meio da articulação das facetas e focos das categorias propriedades, forma de apresentação/expressão, agentes, espaço e tempo. Diante disso, foram estabelecidas as facetas: gênero; registro temporal da trama; gancho temporal; referência histórica; temas representados; estrutura narrativa; natureza da representação; seqüências relevantes; aproximações temáticas da(s) seqüência(s) escolhida(s); sinopse; instrumentos documentais; complementações; informações extrafílmicas e observações. Para a conceituação das facetas e para a inclusão das informações nos campos conceituais, o aporte da teoria do cinema foi de importância singular.

A seguir, são descritas, de forma didática e sucinta, as facetas estabelecidas; porém, talvez haja o prejuízo de algumas informações referentes ao detalhamento técnico. Acredita-se, entretanto, que com esta opção haverá ganho na compreensão das idéias essenciais e formadoras das facetas.

Na mídia, a nomenclatura usada para nomear o gênero de um filme é ampla e repleta de inovações pessoais do enunciador; assim, houve a tentativa de ficar nos gêneros que são tradicionalmente compartilhados na literatura acadêmica e técnica. Ainda, como critério, foi intitulado o gênero predominante na obra fílmica, ficando a nomeação de um subgenêro para inclusão no campo das complementações.

$\mathrm{Na}$ faceta registro temporal, dois focos emergiram: o gancho temporal e a referência histórica. Dedicou-se, no registro temporal, a identificar se a narrativa acontecia no tempo passado, na atualidade ou no futuro. Quando possível, a informação era caracterizada pela datação (ano, década, século). O gancho temporal refere-se ao evento histórico de maior abrangência presente 
na trama, enquanto, na referência histórica, é feita a alusão aos fatos históricos específicos e acentuados na trama.

Quanto à faceta temas representados, procurou-se explicitar os assuntos desenvolvidos no encadeamento das ações na trama. Assim, o tema "[...] corresponde ao resumo da ação, à sua idéia central ou princípio organizador" (AUMONT, 2003, p. 286-287). Ainda, os autores mencionados apóiamse na citação de Barthes, quando elucida que os temas [...] são sempre organizados em estrutura, ou seja, "em rede organizada de obsessões".

A natureza da representação (montagem cinematográfica de imagens visuais e sonoras) foi entendida como documental (realizada exclusivamente como registro documentário), reconstituída (que pretende passar porque busca verossimilhança explicitada), aleatória (é indeterminada, não indicada expressamente no texto fílmico), mista (composta de um ou mais itens anteriormente citados).

Após diversas tentativas de sistematização, optou-se pela nomeação das estruturas narrativas em simples (especificada como linear, binária, circular), ou complexas (especificandose inserção fragmentária, polifônica, aberta, ausente).

Ao se compreender que a seqüência de um filme é “[...] um momento facilmente isolável da história contada por um filme: um seqüenciamento de acontecimentos, em vários planos, cujo conjunto é fortemente unitário" (AUMONT, 2003, p. 268), procurou-se isolar nos filmes o máximo de duas seqüências relevantes que pudessem ser consideradas como emblemáticas para a compreensão da "proposição" da narrativa estética/poética e informativa de determinado filme, além da possibilidade de cada uma delas ser um fragmento representativo do todo fílmico. Agregou-se ainda a esta faceta a possibilidade de menção à aproximação temática da seqüência escolhida, a fim de ser pensada e nomeada como um foco na trama potencializado por seu autor e refletido no espectador.

Diante disso, as seqüências relevantes puderam ser pensadas, em alguns casos, a partir de uma licença poética para sua determinação; em conseqüência, foram designadas como de ação, sexo, drama psicológico, dança, terror, suspense, grandes interpretações, humor, ousadias estéticas, interpretações musicais, documentais, efeitos especiais, tonalidade política e cenas clássicas. Incluiu-se também a aproximação temática da seqüência escolhida, por exemplo, melodrama latino-americano.

As sinopses de filmes, muitas vezes, não são realizadas tendo como função a representação e a recuperação da informação para uma unidade de informação. São construídas a partir da perspectiva de seus realizadores. Contudo, em uma unidade informacional, as sinopses poderão ser feitas considerando-se critérios oriundos de uma diretriz institucional para tal fim, de modo que a construção dos textos sinópticos possa ser orientada por princípios quanto aos aspectos do conteúdo e da redação. Portanto, depois de algumas tentativas de construção das sinopses, chegou-se à seguinte ordem seqüencial e constante dos critérios norteadores: apresentação e objetivo do personagem principal; conflito(s) descritos por meio dos fatos narrativos e personagens; fecho da trama. Quando possível, acentuaram-se o espaço e o tempo dos conflitos. Quanto à forma de apresentação da sinopse, recomenda-se que sua descrição deva ser iniciada por um substantivo e que se evitem os adjetivos. Sempre que um personagem era incluído na sinopse, citava-se o seu nome na trama, além de se relacionarem, entre parênteses, o sobrenome e o prenome do ator/atriz. Por fim, ressalta-se que na sinopse não deve ser inserida a opinião pessoal do analista/indexador.

Nos instrumentos documentais, podem ser incluídos, quando for o caso, os tipos de documentos anteriores e posteriores à filmagem (argumentos, roteiros, artigos de jornais sobre críticas etc.) relacionados ao filme e que porventura existam na unidade de informação.

Nas complementações, podem ser incluídas informações que enriqueçam os demais campos.

O campo informações extrafílmicas e observações é aberto para inserções adicionais e sugestões, como, por exemplo, citar que o filme possui número musical especial, última atuação de um ator, locação especial etc.

Deve ser sublinhado que, nas primeiras versões das matrizes elaboradas, a atenção focalizou e, talvez, desviou-se para a possibilidade tentadora, mas utópica, de construir múltiplas categorias que esgotassem, em grande parte, as possibilidades de análise e de recuperação do conteúdo fílmico. Entretanto, havia uma distância entre a potencialidade da criação exaustiva de categorias e sua efetiva realização no campo empírico, pois havia, como diretriz norteadora da indexação, procedimentos que deveriam permitir a análise e a representação do filme, tendo como base o equilíbrio dos princípios da exaustividade e da especificidade na indexação. Portanto, procurouse afastar a alternativa de uma indexação ambígua, e ainda foi efetivada uma "logística" viável quanto aos procedimentos pragmáticos. 


\section{Rosa Inês de Novais Cordeiro / Tunico Amâncio}

\section{CONSIDERAÇÕES FINAIS}

Neste estudo, o processo de indexação dos filmes, ou seja, da análise de conteúdo dos filmes, foi enfocado e pensado como um processo comunicacional (social) interativo e, portanto, sujeito a um contexto situacional, considerandose ainda que os "estoques de informação" abrigam-se em um espaço social e resultam dele.

A indexação de qualquer documento é um procedimento redutor do conteúdo total de uma fonte de informação, inclusive o filme, mas a prática da indexação, tendo como base a tentativa de analisar o filme mediante o seu potencial informativo, potencializa a possibilita o acesso aos fragmentos do filme e viabiliza a tomada de decisão do usuário sobre a necessidade o acesso e uso do filme. Portanto, parece promissora a possibilidade de a indexação levar em conta a interseção níveis de usuários (grande público ou público leigo, publico iniciado em assuntos filmográficos e o usuário especialista em cinema) com níveis de indexação. A hipótese do "contágio imitativo", conforme a perspectiva de Tarde, necessita ainda de mais testes no universo dos "estoques de informação" de filmes, mas há indícios de resultados satisfatórios.

Os princípios de indexação de filmes que resultaram em categorias que foram estruturadas em um possível modelo de indexação de filmes, entre outros existentes, puderam ser validados com as testagens, embora o universo da amostra possa ser ampliado com os procedimentos da próxima fase da pesquisa.

\section{Artigo recebido em 21/10/2004 e aceito} para publicação em 15/08/2005.

\section{REFERÊNCIAS}

AUMONT, Jacques. A imagem. Campinas: Papirus, 1993. . À quoi pensent les films. Paris: Séguier, 1996. et al. A estética do filme. Campinas: Papirus, 1995.

; MARIE, Michel. Dicionário teórico e crítico de cinema. Campinas: Papirus, 2003.
CASETTI, Francesco. El film y su espectador. 2. ed. Madrid: Cátedra, 1996.

CINEMATECA BRASILEIRA. Manual de catalogação de filmes. São Paulo, 2002.

CORDEIRO, Rosa Inês de Novais. Informação e movimento: uma ciência da arte fílmica. Niterói: UFF, 2000. Programa de Pós-Gradudação em Ciência da Arte.

; ARAÚJO, Christian J. Casselli de; FERNANDES, Lucina P. Representação de filmes para a recuperação da informação: ampliação de uma proposta metodológica experimental de indexação. In: SEMINÁRIO DE INICIAÇÃO CIENTÍFICA E PRÊMIO UFF VASCONCELLOS TORRES, 2000, Niterói. Anais... Niterói: EDUFF, 2000.

GAUTHIER, Guy. Veinte lecciones sobre la imagen y el sentido. Madrid: Cátedra, 1996.

INTERNATIONAL FEDERATION OF FILM ARCHIVES. The FIAF cataloguing rules ofr film archives. München: K. G. Saur, 1991. Disponível em: <http://www.fiafnet.org/pdf/uk/FIAF_Cat_Rules>. Acesso: 4 out. 2004.

LANCASTER, F. W. Bases de dados de imagens e sons. In: Indexação e resumos: teoria e prática. 2. ed. Brasília: Briquet de Lemos, 2004. cap. 13, p. 213-248.

- Da indexação e redação de resumos de obras de ficção. In: . Indexação e resumos: teoria e prática. 2. ed. Brasília: Briquet de Lemos, 2004. cap. 12, p. 199-213.

MOREIRO GONZÁLEZ, José Antoni; ARILlO, José Robelando. O conteúdo da imagem. Curitiba: Ed. UFPR, 2003.

RICHMOND, Phyllis A. Precedent-setting contributions to modern classification. Journal of Documentation, v. 44, n. 3, p. 242-249, 1988.

SHATFORD, S. Analyzing the subject of picture: a theoretical approach. Cataloging 8 Classification Quarterly, v. 6, n. 3, p. 39-62, 1986.

STAM, Robert. Introdução à teoria do cinema. Campinas: Papirus, 2003.

TARDE, Gabriel. Sociologia e subjetividade. Rio de Janeiro: Relume Dumará, 2002.

VANOYE, Francis; GOLIOT-LÉTÉ, Anne. Ensaio sobre a análise fílmica. Campinas: Papirus, 1994.

WILSON, T. D. The work of the british classification group. In: WELLISCH, H.; WILSON, T. D. (Ed.). SUBJECT RETRIEVAL IN THE SEVENTIES, 1971, England. Proceedings... Westport: Greenwood Publishing, 1972. 